\title{
Nota necrológica
}

\section{«In memoriam». Profesor F. Enríquez de Salamanca Lorente, 1927-2005}

Tuve la fortuna de conocerlo hace muchos años en los cursos de Cirugía de la mano que con tanto interés preparaba secuencialmente y donde muchos Cirujanos Plásticos, Traumatólogos y C. Generales despertaron en la cirugía de la mano, gracias al poder didáctico del Dr. Enríquez de Salamanca y profesores invitados.

En el año 1975 siendo Médico Interno Residente fui a su Servicio por primera vez y posteriormente, formándome bajo la tutela del Dr. Vilar, volví a rotar 10 meses del año 1978.

Hijo de Carmen y Fernando, Catedrático de Patología, Médico y Decano de la Facultad de Medicina de la Universidad Complutense de Madrid. Su inicio como universitario en el ICAI se frustra a los pocos años de empezar la guerra civil, fue una suerte para la Medicina, dado que al finalizar la guerra comienza la carrera universitaria, licenciándose como Médico en 1945 con el máximo galardón Premio Nacional Fin de Carrera.

Coincide en New York University con Severo Ochoa becado por el Gobierno Español de la posguerra. Llevaba el germen universitario, por lo cual reconduce su trayectoria al volver a su origen para intentar ser Catedrático de Patología Quirúrgica, pero no estaba ni programada su vida, ni su actitud, ni el tribunal para que así fuera, personalmente le dolió pero no le frustró, dado que supo proyectarse con gran dedicación y esfuerzo hacia otros campos de la medicina, con proyección a la C. plástica y en especial a la mano para la cual acude de nuevo a la ciudad de Boston y California con Boyes.

Creados en Madrid los tres primeros Servicios de C. Plástica, le animan a él para que lleve el Servicio de la Caja de Seguros de Accidentes de Trabajo, en el Paseo de Reina Victoria teniendo como compañeros de los otros Servicios madrileños a los Dres. Sánchez Galindo y Vilar Sancho Altet.

Con motivo de la inauguración del Hospital de Traumatología de la Ciudad Sanitaria de La Paz que llevaba adscrito el primer Servicio integral de Quemados, se reinicia de nuevo su carrera habiendo dado un cualitativo salto hacia la modernidad hospitalaria, tecnológica y dotacional lo que llevó progresivamente a dotarlo como Servicio asistencial-docente y universitario. Posteriormente adscrito a la Facultad de Medicina de la Universidad Autónoma.

No quiero olvidarme de ninguno y por eso no haré citación nominal, pero bien en formación completa o rotacional de meses pasó gran parte de la nómina de Cirujanos Plásticos de nuestro país, como así mismo gran número de cirujanos extranjeros, unos y otros discípulos al fin.

Son aquí, en este centro sanitario, donde se inician sus famosos cursos de Cirugía de la mano por donde desfilan los profesores más brillantes del momento: Tubiana, Morelli, Zancolli. En estos cursos estaba germinando un área de Capacitación Específica: la Cirugía de la Mano. Con la revisión, actualización y puesta al día de las patologías médico quirúrgicas de la mano. De esos momentos son las frases célebres, cuadros con avisos y sentencias sobre la metodología exploratoria quirúrgica y postoperatoria de la mano.

Buen conferenciante, brillante confrontador, didáctico profesor fue pasando la patología de la mano por aquellos cursos en los que a unos abría los ojos hacia un nuevo campo quirúrgico, a otros instruía en una determinada técnica y a otros ayudaba a resolver o proyectar en una nueva expectativa que al volver a su Hospital de origen intentaban desarrollar.

De esos momentos se despierta el interés por la urgencia de la cirugía de la mano, por la reconstrucción completa integral: ósea, tendinosa, nerviosa, asegurando siempre una buena cobertura cutánea y si las condiciones son adversas el programarla como diferida, dado el concepto de que el 
primer tratamiento marca el grado de recuperación futura de la mano. Estamos en unos momentos donde las condiciones favorables para realizar la cirugía de la mano no se daban. Dentro de su faceta docente, especial afición a la anatomía topográfica funcional: la correlación lesión déficit y cómo compensar la paresia, anatomía-función, equilibrio-desequilibrio, agonista antagonista, favorable desfavorable, para él todo era mensurable en la Cirugía paliativa de la mano paralítica.

Elevó la cirugía de la mano a categoría de enfermedad, sentando las bases para que cirujanos generales, traumatólogos o compañeros plásticos disfrutasen explorando, interviniendo o viendo resultados a veces originales. Recuerdo de él su afición a reunir hojas manuscritas para un futuro manual de cirugía de la mano y enfrentarse al tablero de ajedrez, era un reto que podía él evaluar al «contrincante». Amigo de la evaluación constante a sus discípulos, célebres eran sus preguntas sobre el campo operatorio, sus sesiones clínicas de pacientes o de instrumentos o el célebre aparato de laboratorio de quemados que no funcionaba y la promesa de nombramiento si técnicamente lo dominaban.

A veces su autoexigencia le hacía intolerante con algunas circunstancias vitales, no valorando correctamente algún aspecto desconocido para él. Cambió en los años finales de su vida profesional la ajetreada Ciudad Sanitaria por el Hospital Virgen de la Torre donde alcanzo la edad de jubilación, pero no sin antes dejar la semilla del interés por la mano y patologías afines en su descendencia. Hoy Javier, su hijo, puede estar muy orgullo de la semblanza que nos dejó su padre D. Fernando (que el Todopoderoso guarde para siempre).

El pasado XL Congreso de la Sociedad Española de Cirugía Plástica Reparadora y Estética, celebrado en La Coruña bajo la coordinación del Dr. F. Martelo la Sociedad Española de C. Plástica le rindió un merecido homenaje, en un sencillo acto dentro del Congreso. El Dr. Enríquez de Salamanca $(\dagger)$ agradeció con brillantes palabras el acto, ocasión de intercambiar una breve conversación con él sobre el presente y futuro de la especialidad como el la veía.

Falleció el día 23 de Julio hace pues sólo unos meses. Que de todo lo que sembró se recoja a buena cosecha.

Un cariñoso recuerdo a su familia y un abrazo a Javier.

Dr CÉSar Casado.

Jefe del Servicio de Cirugía Plástica Reparadora y Quemados Hospital «La Paz»

Madrid 